Russakoff, A. H. \& Blumberg, H. (I944). Ann. intern. Med. 21, 848.

Sellers, E. A., Lucas, C. C. \& Best, C. H. (1948). Brit. med. F. i, 1061.

Sérégé, H. (1902). C.R. Soc. Biol., Paris, 54, 200.

Seyfarth, C. (1921). Dtsch. med. Wschr. 47, 1222.

Stewart, M. J. (1917). Proc. R. Soc. Med. ro, ro.

Strumpell, A. (1921). Dtsch. med. Wschr. 47, 1219.

Thannhauser, S. J. (1940). Lipidoses, Diseases of Cellular Metabolism. Oxford: University Press.

Tucker, H. F. \& Eckstein, H. C. (1937). F. biol. Chem. 121, 479.

Turnbull, H. M. (1917). Proc. R. Soc. Med. 10, 47.

Vigneaud, V. du (1942). Harvey Lect. 43, 39.

Wakim, K. G. \& Mann, F. C. (1942). Arch. Path. 33, 198.

Weichselbaum, T. E. (1935). Quart. F. exp. Physiol. 25, $3^{6} 3$.

\title{
Nutrition and Disease in Veterinary Research
}

\author{
By H. H. GREEN \\ Veterinary Laboratory, Ministry of Agriculture, Weybridge, Surrey
}

\section{Introduction}

The invitation to read a paper on nutrition in relation to veterinary research was accompanied by a warning from the Secretary of the Scottish Committee to keep off 'deficiency diseases' per se, to shun any topics discussed before the Society in the past, to try to deal with indirect rather than direct associations between diseases of the larger domesticated animals and their food, to be as pastoral as possible by dwelling mainly on ruminants, and to try to make the paper read like a novelette.

This behest rules out vitamin deficiencies, common enough in poultry reared on the intensive system and in indoor pigs before reaching bacon weight, although rare in grazing animals. It also rules out deficiencies of major mineral elements such as phosphorus, as manifested in aphosphorosis of ruminants (Theiler \& Green, $193 \mathrm{I}-2$ ), and of minor minerals or trace elements (Green, I944) such as cobalt, lack of which was first established in Australasia but is now well recognized in certain sheep-rearing pastures in Britain. It does not rule out injurious minor elements entirely, but the most interesting British example, the molybdenosis of central Somerset, is excluded by its earlier discussion before the society by Ferguson (1944). It leaves open the vast topic of pasture plants injurious to livestock in virtue of toxic principles, ranging from poisons in the conventional sense of causing death rapidly, to photosensitizing substances producing diseases such as 'geeldikkop' in South Africa or 'yellowses' in Scotland, or unidentified toxins with a trigger action setting up a sequence of pathological changes terminating in clinical symptoms and death so long after ingestion that the origin of disaster is obscure, as in 'gousiekte' (caused by eating Vangueria pygmoeum) in South Africa where 'trekking sheep' spending only a day or two on one pasture may die of progressive myocarditis a month or two later on another. But such a topic is not what the Committee had in mind, and serves only to indicate some of the problems which differentiate the spheres of activity of medical and veterinary research workers. 
To keep within the terms of reference I therefore propose to consider briefly: ( $\mathrm{r}$ ) diseases of bacterial origin indirectly associated with pastures; (2) malnutrition in relation to susceptibility to transmissible disease; (3) components of ostensibly good pastures harmful in excess; and (4) disease controllable by prophylactic or therapeutic use of substances already present in pastures in apparent abundance.

\section{(I) Diseases of bacterial origin indirectly associated with pastures}

Perhaps the best illustration of this is the disease 'lamsiekte' of cattle in South Africa, the aetiology of which was first clarified by Theiler and co-workers in I919, (for a review see Theiler \& Green, 193 I-2), and soon after identified with similar diseases in other parts of the world, such as the 'bulbar paralysis' of Australia and the 'loin disease' of 'Texas. The primary cause was shown to be a toxicogenic saprophyte, later identified as Clostridium botulinum 'Type D, which multiplied in carcasses of animals, large or small, that died on the veld from any cause whatever. In large-scale ranch farming on poor land, carrion material is generally left to the eagles or allowed to rot unburied unless directly transmissible disease, such as anthrax, is suspected. Since healthy herbivores do not touch skeletal debris the idea of botulism did not occur to the small team of investigators for a long time, despite the fact that a form of pica or depraved appetite was common in cattle in 'lamsiekte' areas. The fact that pica was equally common in areas in which the disease was unknown befogged their wits. Indeed, the fact that both 'lamsiekte' and pica could be prevalent on one farm and absent on an apparently identical neighbouring farm seemed to negative an association which leaped into prominence as investigations proceeded. Innumerable transmission experiments had failed, which is not surprising when it is remembered that $\mathrm{Cl}$. botulinum does not infect the living animal, but only the dead, and that decayed carcass debris is normally quite safe. The observation, however, that once 'lamsiekte' was recorded on a farm the mortality incidence tended to increase led to the purchase of an abandoned farm of about 20,000 acres in Bechuanaland specifically for experimental purposes. In 1918 , after several years' puzzling over an annual mortality incidence of about $25 \%$ amongst freshly introduced cattle, suspicion finally descended on old bones-an odd suspicion explained by the sequence of discovery. One large fenced paddock near the homestead was used as a hospital camp to which 'lamsiekte' cases could be transferred and which could be used for contact experiments. It rapidly became a carcass camp with abundant skeletal debris, and finally certain healthy animals introduced into it were observed to die of the disease within a few days of consuming old bones. These animals had displayed pronounced pica, while their more normal fellows left the skeletal debris untouched. By collecting the suspected bones and forcibly administering a few pounds in crushed form to a normal ox, successful experimental production of 'lamsiekte' was achieved, and the idea of associating the toxin of a toxicogenic saprophyte with osteophagia at once leaped to the mind. The whole aetiological picture was then rapidly painted in. Cultures of mixed anaerobes got by inoculating the incriminated rotten bones into minced liver tissue provided material so toxic that a few grammes were rapidly fatal to a full-grown ox. Liberal feeding of clean commercial bonemeal 
abolished the osteophagia of susceptible cattle in a few weeks, and they could then be turned into the fatal carcass camp with impunity. The osteophagia, or abnormal craving for bones, was found to be caused by phosphorus deficiency in the grass, and could be abolished by feeding sodium phosphate or bran or any food rich in phosphorus, or by fertilizing the soil with phosphates. Degrees of osteophagia were measured by offering to the cattle in succession stinking bones, slightly smelly bones and sun-bleached sweet bones, all of course from non-toxic carcasses. Only those individuals with depraved appetite sufficiently definite to chew slightly smelly bones were in real danger of 'lamsiekte' from consumption of toxic carcass debris.

The aetiological sequence became clear, and involved nutrition directly. It was: (a) phosphorus deficiency of the soil and pasture; (b) aphosphorosis in the animal, leading to osteophagia which, if sufficiently pronounced, led to consumption of carcass debris; $(c)$ which, if it happened to be infected with $C l$. botulinum, was toxic and caused 'lamsiekte'. 'The chain could be broken at any point, and in practice a ration of a few ounces of bonemeal per head daily, combined with removal of gross carcass debris from the veld, sufficed to effect a dramatic reduction of the mortality rate in a herd of 600 cattle from 25 to $\mathrm{r} \%$ in a single year. Immunity could also be built up by the use of toxoid, but this of course left the adverse nutritional effects of aphosphorosis unaffected. The use of bonemeal effected amazing improvement in scrub cattle, increasing the growth rate, fertility rate and milk yield in animals whose previous poor production had been attributed to bad ancestry and malnutrition in the non-specific sense of inadequate calories and protein. It also led to the identification of another disease, 'styfsiekte', which is simply bovine osteomalacia in areas in which phosphorus deficiency is extreme but in which the animals do not die of 'lamsiekte' because Cl. botulinum is absent.

The spread of 'lamsiekte' on phosphorus-deficient farms is easy to understand. A single animal introduced into a herd from a distant infected farm may bring in spores of the non-pathogenic but toxicogenic saprophyte in its intestinal tract. If this animal survives a few weeks the few spores originally present are eliminated in its faeces and represent only a negligible contamination of a large ranch, but if it dies from any cause whatever within a few days, invasion of the soft tissues may follow, with enormous multiplication of the organism. Ordinary putrefactive flora of course usually dominates decomposition of the carcass but, if $\mathrm{Cl}$. botulinum does multiply, the soil is heavily contaminated with spores in situ and these can be blown by wind to infect any dead debris at all, even small game, rodents, lizards and tortoises. Subsequent deaths from 'lamsiekte' rapidly heap up the infection.

The dreaded 'lamsiekte' is now a disease of the past, or should be, and can almost be regarded as a blessing in disguise which focused attention on the economically more important nutritional problem of phosphorus deficiency per se. This nutritional aspect is brought out in illustrations from later publications (Theiler, Green \& du Toit, 1924, 1927).

It may be added that pronounced phosphorus deficiency is rare in British pastures and that the concatenation of circumstances leading to widespread botulism is unknown, but that the disease may crop up sporadically. There is a classical case of a dead 
rat in a hay loft reaching the manger of a cow and causing fatal botulism. Those concerned with destruction of rats by poison might remember the observation.

Of other types of bacterial diseases associated with animal nutrition two may be mentioned. One is represented by enterotoxaemias, where the causal organism multiplies and produces its toxin within the alimentary tract. The other is not associated with nutrition proper, but only with agricultural processes designed to improve it. Increased incidence of both may be associated with improved grassland management.

When old grassland is ploughed up and reseeded, considerable soil surfaces are exposed until such time as a new dense carpet of vegetation is formed, and for some time soil contamination of pasture is enhanced. Certain pathogenic organisms can live in association with normal soil flora and some soil organisms can acquire pathogenic characteristics. Increased incidence of 'blackleg' on new leys, caused by penetration of $C l$. chauvei through abrasions in the skin, is sometimes attributed to this.

Of greater theoretical nutritional interest are the enterotoxaemias, where the toxins are absorbed through the intestinal tract. Greig (1936) expressed the view that in Scottish 'braxy' of sheep, caused by Vibrion septique, digestive disorders associated with decreased gastric secretion and increased abomasal $\mathrm{pH}$ may be conducive to vegetative proliferation and toxin production of the organism. Bennetts (1932, i936), writing of 'pulpy kidney', an enterotoxaemia of sheep in Australia caused by $\mathrm{Cl}$. ovitoxicum ( $\mathrm{Cl}$. welchii, Type D) emphasized the greater prevalence amongst fat wellnourished animals than amongst those in poor condition, and suggested that temporary sluggishness of the small bowel resulting from lack of exercise and low content of fibre in the food led to multiplication of a normal gastro-intestinal inhabitant. Bennetts drew special attention to the high incidence on regularly cultivated land under conditions of pasture improvement, as compared with absence of the disease in bush country.

Since, however, the well-nourished animal is the profitable one and precise information on nutritional factors is scanty, practical measures of control take the form of immunization with $\mathrm{Cl}$. ovitoxicum anaculture. The main difficulty is not in prevention but in predicting the location of new appearances of the disease. As mortality tends to be very high in flocks not previously affected, heavy losses may occur before régular precautionary measures can be taken.

\section{(2) Malnutrition in relation to susceptibility to transmissible disease}

In the popular mind the belief is prevalent that malnutrition increases susceptibility to transmissible diseases, and in general this is doubtless true, although in many instances the bad hygiene commonly associated with conditions of malnutrition is the more important factor. But the reverse is not infrequently the case, and amongst diseases of farm stock, foot-and-mouth disease is clearly recognized as affecting large, well-nourished individuals more than ill-nourished ones. This aspect of infection with the causal virus has been investigated by Edwards (1937) in a series of controlled experiments on rats, guinea-pigs and hedgehogs. Half-grown rats rapidly gaining weight on a highly nutritious diet could be infected with a very much smaller dose of 
virus, and showed much more severe lesions than those less well fed. A varied and rich diet had most effect in increasing susceptibility, especially when the additions to the ostensibly adequate diet included liver and carrots. The experiments appeared to show that susceptibility on a poor diet increased quickly when special additions were made, and that after a period on a highly nutritious diet the capacity for reacting strongly to inoculation persisted for some weeks on a poor diet. 'The conclusion was reached that both rats and guinea-pigs were most susceptible in middle life and when growing in first-rate condition.

Edwards suggested that nutritional factors were also concerned in the annual rise and fall in the natural incidence of foot-and-mouth disease in cattle in India, and related these to season, rainfall and herbage. In an epizootic in Southern Rhodesia Bevan (1932, 1933) reported that infectivity was lower in the dry season when fodder was scarce, and that lesions were less pronounced, than under good nutritional conditions after the seasonal rains.

The converse case of increased susceptibility under conditions of malnutrition is well illustrated by helminth infections. Sheep, for instance, which have developed substantial resistance to the stomach worm Haemonchus contortus may become susceptible again on an inadequate diet and throw off the severe infection again on a full diet. As Taylor (1944) points out, some workers have maintained that resistance of the host to helminthiasis, and also to diseases caused by microscopic parasites, is not affected by nutritional insufficiency unless this is so pronounced as to affect the general condition of the animal severely, and some epidemiologists have expressed the view that only the most extreme malnutrition, such as frank starvation or gross lack of vitamins amongst large sections of a population, can be of real importance in affecting the severity of epidemic diseases. These conditions are unlikely to exist in human populations such as our own, but it must be remembered that grazing animals, even in Britain, are less favourably placed and are frequently forced to exist on a very low plane of nutrition for quite long periods. In some sheep-grazing areas the animals may lose a quarter of their weight during the winter months, during which time the ewes are in gestation, and store cattle in winter are often kept only just alive in a state of progressive emaciation on nothing but the poorest of hay or straw in the hope that they can still be fattened for market in summer. The nutritional stress also comes at a period when the young animal ought to be establishing its immunity and throwing off the parasites acquired during the summer. As a result the parasites remain, or increase in number if the animal is still grazing, so accentuating still further the loss in condition.

Taylor (1944), in discussing development of immunity to parasites, and 'premunition' or the resistance of a host to further infestation with a parasite it is already carrying, stresses the importance of the study of mutual reactions between a mammalian host and its parasitic community, pointing out that small numbers of helminths are normal inhabitants of all healthy sheep, and that it is only when the natural equilibrium of 'happy worms in happy sheep' is seriously disturbed that helminthiasis becomes an economic problem. Malnutrition disturbs the balance, and operates most seriously in lambs before 'age immunity' is developed. Taylor also points out how the botanical structure of different pasture plants may affect the ease with which certain parasitic 
larvas reach their host, and hints that increased prevalence of highly nutritious clover may facilitate their task.

Of common bacterial diseases possibly influenced by malnutrition we may mention 'necrotic enteritis'. of young pigs, caused by Salmonella suipestifer and generally regarded as more prevalent under conditions of bad hygiene and poor feeding. A noninfective form of enteritis with necrosis can also be experimentally produced on diets deficient in nicotinic acid, and occasional outbreaks of nutritional necrotic enteritis have been reported in which Salm. suipestifer infection could not be incriminated. It might, therefore, be supposed that malnutrition would decrease resistance to infection by reducing the integrity of the intestinal wall, but limited experiments at Weybridge, abandoned during the war, provided little support for this view. The virulence of the particular strain of organism used seemed to be the important factor.

\section{(3) Components of ostensibly good pastures harmful in excess}

Grass, the staple food of ruminants, is a much more mysterious complex than is commonly supposed and, apart from its major nutrients, such as protein, carbohydrates and minerals required in large amount for structural purposes, and minor nutrients such as vitamins and essential trace elements, contains physiologically active compounds which may affect the consuming animal for better or worse.

Among these substances we may mention two which have come into prominence very recently, which are probably present in the leaves of many edible plants, but which in large amounts can produce unexpected effects. One is a principle recently extracted by Ferguson (1948) both from pasture grass and from clover, which inhibits activity of smooth muscle and which may be found to have a bearing on the occurrence of 'bloat' in cattle and sheep, a condition which commonly occurs after transference from dry stall rations to rapidly growing pasture grass. The animals stuff themselves with easily fermentable food and the rumen becomes distended with gas faster than it can be got rid of by the normal protective device of belching. The opening into the oesophagus may be occluded and the gas tension in the stomach system increase to the point of suffocation or rupture unless relieved by artificial puncture. Interference with normal muscular function by an inhibitory factor in new leys may well be a feature in the aetiology of 'bloat', although investigation has not proceeded to the stage of assessing its importance.

The other fascinating instance is the report by Bennetts, Underwood \& Shier (1946) in Australia of the presence of an oestrogenic substance, or 'oestrogen-potentiating principle', in relatively large amounts in the Dwalanup early strain of subterranean clover, locally developed for use in pasture-improvement schemes. In moderate amounts this is a valuable feeding plant, but where it exceeds about $30 \%$ of the total farm grazing, and in particular when it becomes the main food of the sheep, a serious breeding problem has arisen over the last few years. The problem has three manifestations in the ewe; infertility apparently arising from failure of conception, maternal dystocia associated with uterine inertia and involving the death of the full-term foetus, and prolapse of the uterus, which occurs typically some months after the lambing season 
and which may even affect unbred ewes. Virgin and unbred females also commonly show marked mammary development and copious milk secretion. Rams appear to be unaffected, but castrated males may show squamous metaplasia in the secondary sex organs and occasionally develop an accessory organ lined with vaginal epithelium. A cystic endometrium could be produced regularly in guinea-pigs within a few weeks on an exclusive diet of the green plant, and it is of comparative interest to note that the most characteristic pathological finding is one analogous to the cystic hyperplasia of the endometrium in the human female commonly attributed to hormonal imbalance. In his second paper Bennetts (1946) describes the histology of the metaplasia in the sex organs of castrated males, and shows that almost identical responses can be induced experimentally in wethers by administration of $1200 \mathrm{mg}$. of stilboestrol over a period of 4 weeks.

In practice, the sheep is the only farm animal affected. Cattle and horses bred on the same pastures have as yet shown no evidence of any corresponding problem. The pioneer work of Bennetts is now being developed by his colleagues on the biochemical side, including sex hormone assays on plants.

\section{(4) Disease controllable by prophylactic or therapeutic use of substances already present in pastures in apparent abundance}

The outstanding instance of this is represented by a variety of hypocupraemic conditions in sheep and cattle, which respond to administration of copper but in which there is an ample supply of this essential trace element already present in the pasture.

The first observations on the practical significance of copper in the control of certain diseases of ruminants came from Western Australia (for a review see Green, 1944) where, however, they were regarded as arising from genuine copper deficiency because they occurred on pastures very low in copper content-below 5 p.p.m. in the dry matter, and commonly below 3 p.p.m., as compared with common normal values of $7^{-1} 5$ p.p.m. or more in unaffected pastures or in healthy European pastures.

Copper values of blood and liver were low, and the disorders could be prevented by supplementing with copper salts, or top-dressing the pastures with copper sulphate, so that the chain of evidence seemed to be complete. Apart from extreme copper deficiency manifested as 'falling disease' in dairy cattle, the most serious disorder was 'enzootic ataxia of lambs', a demyelination disease developing in the foetus in the later stages of gestation and responsible for heavy mortality in the early weeks of life. The mother ewes were relatively healthy, but their blood copper was very low. Administration of copper sulphate during pregnancy prevented enzootic ataxia and, since affected pastures were always low in copper, there was no reason for regarding the aetiology as other than straight copper deficiency.

When, however, the corresponding condition in Britain, long known as 'swayback of lambs', came to be investigated in detail, it was found that, although the two diseases appeared to be identical in every way, both being associated with hypocupraemia in the mothers, and both showing excellent prophylactic response to small copper supplements in late gestation, swayback occurred quite independently of the copper content of the 
pastures. It was prevalent on pastures containing the normal 10 p.p.m. in the dry matter, even on pastures high in copper ( $15-25$ p.p.m.), whereas figures below the critical level of 5 p.p.m. in Australia were very rare.

It became obvious that something else besides copper was involved, and an experiment at the Veterinary Laboratory of the Ministry of Agriculture a few years ago provided direct evidence of this. 'Twenty ewes, all with very low blood-copper values and all with a history of having delivered a swayback lamb in the past, were brought to Weybridge just after tupping, from a farm in Derbyshire on which the average annual incidence of swayback was about $20 \%$ of the lamb crop, but on which the copper content of the pasture was high-average 15 p.p.m. with range 7-23 p.p.m. At Weybridge they were kept indoors on a selected ration containing only 5 p.p.m. (cereal and oat straw low in copper). In spite of the reduction of the daily copper intake to about one-third, blood copper rose quite rapidly and no swayback occurred amongst their lambs. The following year the experiment was repeated with a fresh set of ewes, but the oat straw was replaced by hay brought from the affected farm. This time the blood-copper values remained low and four out of the twenty lambs born at full term were affected with swayback, an incidence of $20 \%$, similar to that on the affected farm at the same lambing time. The conclusion was drawn that some other substance was present in the hay which either locked up the copper in a form unavailable in the digestive tract of the animal or interfered in some way with the copper metabolism of the animal itself. No satisfactory ideas of the nature of the unknown substance, or of any other intercurrent predisposing disorder, are forthcoming at present, although all the obvious ones have been experimentally investigated. In passing, it is difficult to resist mention of the converse problem of enzootic jaundice in sheep in eastern Australia, where an unknown factor operates in such a way as to cause enormous retention of copper in the liver and leads to death with the symptoms of copper poisoning on pastures perfectly normal in copper content.

Within the last 2 years in Britain, hypocupraemic conditions responsive to administration of copper salts have been encountered in cattle in an almost bewildering variety of clinical forms, from 'Shropshire scours of cows' to 'copper cachexia of Caithness calves'; but nothing resembling the neonatal demyelination disease of lambs has appeared in calves.

The whole position is very obscure, and a blood-copper survey of British cattle is being undertaken this year by Weybridge in collaboration with Veterinary Investigation Officers in the different counties.

\section{REFERENCES}

Bennetts, H. W. (1932). Bull. Coun. sci. industr. Res. Aust. no. 57.

Bennetts, H. W. (1936). Aust. vet. . 12, 196.

Bennetts, H. W. ( 1946). Aust. vet. F. 22, 70.

Bennetts, H. W., Underwood, F. J. \& Shier, F. L. (1946). Aust. vet. F, 22, 2.

Bevan, L. E. W. (1932). Trans. R. Soc. trop. Med. Hyg. 26, 89.

Bevan, L. E. W. (1933). Trans. R. Soc. trop. Med. Hyg. 27, 105.

Edwards, J. T. (1937). Fifth Progress Report of the Foot-and-Mouth Disease Research Committee, Ministry of Agriculture and Fisheries, p. 195. I -ondon: H.M. Stationery Office.

Ferguson, W. S. (1944). Proc. Nutr. Soc. I, 215.

Ferguson, W. S. (1948). Nature, Lond., 16r, 816. 
Greig, J. R. (1936). Congr. int. Path. Comp. 111, 2, 424.

Green, H. H. (1925). Physiol. Rev. 5, 336.

Green, H. H. (1044). Proc. Nutr. Soc. 1, 177.

Taylor, E. L. (1944). Endeavour, 3, 150.

Theiler, A. (1919). Fmr's Whly, Bloemfontein, 7 May.

Theiler, A. \& Green, H. H. (1931-2). Nutr. Abstr. Rev. 1, 359.

Theiler, A., Green, H. H. \& du Toit, P. J. (1924). J. Dep. Agric., S.Afr., 8, 460.

Theiler, A., Green, H. H. \& du Toit, P. J. (1927). F. agric. Sci. 17, 291.

\title{
FIFTIETH SCIENTIFIC MEETING
}

ROYAL SOCIETY OF ARTS, JOHN ADAM STREET, ADELPHI, LONDON, W.C. 2

23 OCTOBER $194^{8}$

\section{ANTIVITAMINS IN FOOD}

Chairman: SIR EDWARD MELLANBY, G.B.E., K.C.B., F.R.S. Medical Research Council, $3^{8}$ Old Queen Street, London, S.W. I

\section{Antivitamins and Other Factors Influencing Vitamin Activity}

\author{
By Leslie J. HaRris \\ Dunn Nutritional Laboratory, University of Cambridge and Medical Research Council
}

\section{Development of the concept of antivitamins}

When, at the end of the last century, Eijkman (1890, 1897, 1906) earned for himself the distinction of being the first to investigate a vitamin deficiency disease experimentally in an animal, namely beriberi in the hen, he did in fact also enunciate what amounted to the theory of a vitamin and its corresponding antivitamin, although of course he did not use these words. What he said was that beriberi was caused by an excess of carbohydrate in the diet, and that an antidote was present in the rice germ, which counteracted the effect of the excess of carbohydrate. This statement is quite unexceptionable, even as read to-day in the light of the most recent knowledge. We now know that the antidote, the vitamin $B_{1}$ in the rice germ, is indeed needed by the animal organism to enable it to metabolize carbohydrate, and also that carbohydrate is a beriberi-producing agent, in the sense that the more carbohydrate there is present in the diet, the more vitamin $B_{1}$ is needed with it. Thus, a rat can be cured of experimental beriberi either by giving it more vitamin $B_{1}$ or by replacing the carbohydrate in its diet by more fat. It is, therefore, quite legitimate to regard carbohydrate as an antivitamin factor, operating against vitamin $B_{1}$, the term antivitamin being used in its widest sense.

This concept of vitàmins as mere antidotes, however, in the way that Eijkman regarded the curative substance in rice germ as an antidote, failed no doubt to emphasize 